\title{
El cannabis y sus derivados en el derecho penal español
}

Herrero Alvarez, S.

Abogado

Dirigir correspondencia: Sergio Herrero Alvarez . c/Pintor Mariano Moré 22, 3 A. 33206 Gijón

\section{Resumen}

Este artículo examina la regulación de las drogas en el derecho español, para lo cual estudia el Código Penal de 1995, actualmente vigente, y las sentencias del Tribunal Supremo sobre esta materia. Éstas últimas resultan muy importantes ante la falta de precisión legal en algunos aspectos. España considera como drogas ilícitas las sustancias catalogadas en los tratados internacionales existentes, entre las que se incluyen el cannabis y todos sus derivados. El consumo de drogas ilegales es sancionable administrativamente con multas, pero no constituye delito. Tampoco es delito la tenencia de drogas para el consumo propio. El tráfico de drogas es delito penado con prisión, cuya duración depende, en parte, de la nocividad de la sustancia y, en parte, de la gravedad de la conducta delictiva. El Código Penal distingue entre drogas "duras" y "blandas", en función del peligro que la sustancia suponga para la salud de sus consumidores. El cannabis y sus derivados se incluyen en la categoría legal menos grave, y su tráfico se sanciona con pena mínima de un año de prisión y pena máxima que puede llegar a seis años y nueve meses de prisión.

Palabras clave: Código penal, cannabis, jurisprudencia, penas, trafico de drogas, autoconsumo, España.

\section{INTRODUCCIÓN}

a regulación que cualquier ordenamiento jurídico adopte sobre las drogas ha de incluir, en primer lugar, la propia definición y delimitación precisa de las sustan-

\section{Summary}

A review of the regulations of the use and abuse of cannabis under Spanish Penal Code from 1995 and the sentences given by the Supreme Court. Cannabis and its derivatives are catalogued and considered to be illicit drugs as in the majority of other European countries.

Consumption and possession of cannabis is permitted by law. Trafficking and dissemination, on the other hand, are not permitted. Punishment of trafficking and dissemination depends on the risk to general health status, toxicity, the addictive power and severity of the delinquent behaviour.

The Spanish Penal Code (1995) distinguishes clearly between "soft" and "hard" drugs, based on the risk of these substances for the health of the consumer.

Cannabis and its derivatives are included in the category of less serious drug-related crimes and the trafficking of such is punishable with a minimum of one year and the maximum of 6 years and 9 months in prison.

Key words: Cannabis, Penal Code, Jurisprudence, punishment, illicit traffic, self-consumption, Spain.

cias que englobamos en ese concepto legal de "droga". Una vez acotado el mismo, el Estado ha de decidir la legalidad o ilegalidad de la distribución de esas sustancias. De optarse por la ilegalidad, el tráfico o suministro de esos productos puede ser sancionado 
administrativamente o mediante la aplicación de penas. En cualquiera de los casos, puede establecerse una sanción o pena única para cualquier conducta de tráfico ilegal de drogas o castigarse más gravemente ciertas actuaciones. A su vez, esa diferente gravedad de algunas acciones puede relacionarse con el tipo de drogas objeto del tráfico, si se consideran algunas de ellas como más nocivas que otras, en cuyo caso habrá que distinguir legalmente dos o más categorías de drogas.

La solución de las cuestiones expuestas en el ordenamiento jurídico español, en lo relativo al cannabis y sus derivados, constituye el objeto del presente capítulo, en el cual analizaremos el tratamiento de las sustancias que se consideran como drogas en nuestro derecho, las sanciones penales correspondientes y los criterios de graduación de la gravedad de las mismas, así como los principales problemas interpretativos y probatorios surgidos en la práxis de los tribunales.

Como veremos, España, en cumplimiento de los tratados internacionales suscritos, castiga penalmente el tráfico ilícito de drogas, entre las que se encuentran todos los derivados cannábicos con efectos psicoactivos, si bien la ley española diferencia dos tipos de drogas, "duras" y "blandas", en función del peligro que la sustancia suponga para la salud de sus consumidores.

La regulación de los delitos relativos al tráfico ilícito de drogas se encuentra, en la legislación española, en los artículos 368 y siguientes del Código Penal de 1995, en vigor desde el día 25 de mayo de 1996.

El artículo 368 del Código, eje de toda la regulación examinada, sanciona a quienes "ejecuten actos de cultivo, elaboración o tráfico, o de otro modo promuevan, favorezcan o faciliten el consumo ilegal de drogas tóxicas, estupefacientes o sustancias psicotrópicas, o las posean con aquellos fines". La pena correspondiente a los responsables de esos delitos oscilará entre tres y nueve años de prisión, cuando la droga objeto de tráfico sea una sustancia o producto "que causen grave daño a la salud", y se mantendrá entre uno y tres años de prisión en los demás casos, es decir, cuando la droga de que se trate no sea gravemente dañina. Además, en todos los supuestos, la pena privativa de libertad irá acompañada de otra pena de multa, cuya cuantía dependerá del valor de la droga, suponiendo entre el tanto y el triplo de dicho valor, si se trata de sustancias gravemente dañinas, y entre el tanto y el duplo cuando se trafique con otras sustancias.

Por otra parte, el artículo 369 del Código Penal tipifica nueve supuestos distintos en los que las penas de prisión que han de imponerse serán las superiores en un grado a las establecidas en el artículo 368. Finalmente, el artículo 370 crea unos tipos delictivos superagravados, en los que las penas de prisión a imponer son las superiores en dos grados a las penas básicas del primer artículo citado. A todo ello ha de añadirse la existencia, junto con las penas de prisión indicadas y las multas correspondientes en cada caso, de diversas penas de inhabilitación detalladas en el artículo 372.

Del conjunto de preceptos mencionados, y de los demás relativos al tráfico ilícito de drogas, nacen las cuestiones que a continuación vamos a estudiar. Es de advertir que, por encima del interés que pudieran presentar algunas tesis doctrinales, lo relevante, objetiva y prácticamente, tanto para el jurista como para los profesionales del ámbito de la salud, es conocer en cada extremo cual sea la jurisprudencia al respecto, dado que, ante la indefinición legal en algunos aspectos, ha sido el Tribunal Supremo quien ha tenido la última y decisiva palabra.

\section{CONCEPTO DE DROGA ILEGAL}

La mera lectura del artículo 368 del Código Penal (en adelante CP) permite comprobar que este cuerpo legal no define el objeto material del delito descrito. La ley penal no ofrece un concepto de droga ilegal, limitándose a considerar como tales, las sustancias tóxicas, estupefacientes y psicotrópicas, mas sin enumerarlas ni definir sus características. 


\section{CUADRO 1. ARTÍ́CULO 368 CÓdIGO PENAL}

Los que ejecuten actos de cultivo, elaboración o tráfico, o de otro modo promuevan, favorezcan o faciliten el consumo ilegal de drogas tóxicas, estupefacientes o sustancias psicotrópicas, o las posean con aquellos fines, serán castigados con las penas de prisión de tres a nueve años y multa del tanto al triplo del valor de la droga objeto del delito si se tratare de sustancias o productos que causen grave daño a la salud, y de prisión de uno a tres años y multa del tanto al duplo en los demás casos.

Se trata de lo que se denomina una ley penal en blanco, es decir, una norma penal incompleta en la que la conducta sancionable no se encuentra totalmente descrita en ella, debiendo acudirse, para su integración a otra norma distinta, de naturaleza extrapenal, con cuyo indispensable complemento resulta suficientemente precisada cual es la actuación punible. La constitucionalidad de este tipo de construcciones normativas ha sido admitida por el Tribunal Constitucional español, fundamentalmente en sus sentencias (en adelante STC) 62/1982, 122/1987 y 127/1990.

El Tribunal Supremo ha mantenido reiteradamente la consideración como norma penal en blanco del anterior artículo 344 del Código Penal de 1973, derogado por el actualmente vigente pero textualmente coincidente en este aspecto con el nuevo artículo 368 CP. En tal dirección se pronuncia, entre muchas otras, en sus sentencias (STS, en adelante) de 11 de octubre de 1974, 22 de junio de 1981, 25 de octubre de 1982, 4 de febrero de 1984, 7 de mayo de 1984, 15 de noviembre de 1984, 19 de enero de 1985, 15 de julio de 1985, 4 de marzo de 1988, 12 de julio de 1990, 24 de diciembre de 1992, 28 de abril de 1994, 25 de mayo 1994, 27 de setiembre de 1995, 5 de febrero de 1996, 18 de marzo de 1996 y 11 de setiembre de 1996). En ese mismo sentido se inclina la doctrina penal mayoritaria.

El artículo 368 del Código, considerado pues como ley penal en blanco, deberá ser completado con la legislación administrativa relativa a las drogas ilegales. La Ley de 8 de abril de 1967 sobre estupefacientes remite a su vez a los listados de sustancias contenidos en los Convenios internacionales de los que España es parte, de forma que la inclusión o no de una sustancia determinada en esos listas internacionales, periódicamente actualizadas, lo que determine su consideración legal como droga a efectos penales en nuestro ordenamiento jurídico, y la consecuente persecución de su posible tráfico.

El llamado Convenio Único sobre estupefacientes, de 30 de setiembre de 1961, ratificado por España el 3 de setiembre de 1.966, es el primero de los tratados internacionales que complementan y concretan la ley española. Su texto engloba como anexos cuatro listas de sustancias. La lista I comprende, entre otros productos, el opio, la heroína, la morfina, la metadona, la cocaína y el cannabis. La lista II incluye la codeína y el dextropropoxifeno. La lista III se refiere a preparados que no se prestan a uso indebido y, finalmente, la lista IV se dedica a las mezclas o preparados, sólidos o líquidos, que contengan las sustancias de las dos primeras listas. La citada Ley española de 8 de abril de 1.967 dispone, en su artículo 2, que se consideran estupefacientes las sustancias incluidas en las listas I, II y IV del Convenio Único, así como también, en lo sucesivo, aquellas otras que se incorporen al Convenio en el ámbito internacional, o en el ámbito nacional por el procedimiento reglamentario que se establece, que se ha ido ejecutando posteriormente y hasta el momento a través de diversas órdenes ministeriales.

El otro texto internacional relativo a estas materias, que merece siquiera una sucinta mención, es el Convenio de Viena sobre sustancias psicotrópicas de 21 de febrero de 1971, que cuenta con dos anexos, el primero con cuatro listas de sustancias psicotrópicas, referidas respectivamente a alucinógenos 
(LSD, THC, DMT, STP, DOM y otros), anfetaminas, barbitúricos y otras sustancias (tales como la anfepramona, el meprobamato y la metacualona). Por su parte el segundo anexo del Convenio comprende y relaciona sustancias que, no siendo propiamente psicotrópicas, se consideran asimilables a ellas: entre otras sustancias, las benzodiazepinas, el fenproporex y la etilanfetamina. Al igual que ocurre con el Convenio sobre estupefacientes, también éste sobre psicotrópicos contiene un mecanismo de actualización periódica de las sustancias incluidas en sus listas anexas.

Recopilando la clara doctrina jurisprudencial existente, es especialmente ilustrativa la STS de 8 de noviembre de 1995 que afirma, refiriéndose al anterior artículo 344 del Código Penal de 1973, lo que sigue:

"Si bien nuestro art. 344 no define que debe entenderse por sustancia estupefaciente, ello se encuentra en la propia normativa, en el Convenio Único de las Naciones Unidas de 30 de marzo de 1961, que fue ratificado por España, mediante instrumento de 3 de febrero de 1966, prescribiendo este en su apartado $\mathrm{J}$ de su art. $1^{\circ}$ que se reputan estupefacientes a cualquiera de las sustancias que se insertan en las listas 1 y 2 del Anexo, añadiendo el art. $2^{\circ}$ que asimismo las demás que adquieran tal consideración en el ámbito internacional con relación a dicho Convenio y en el nacional por la reglamentación que se establezca y también se reputan las incluidas en la lista 4 - sentencia de 18 de diciembre de 1981 -. Pero la Convención Única de 1961 fue enmendada por el Protocolo de la Modificación de tal Convención de 25 de marzo de 1972, cuyo texto de 8 de agosto de 1975 fue acogido por España y publicado en el BOE de 4 de noviembre de 1981, que en su art. $1^{\circ}$ contiene las distintas definiciones de los conceptos usadas en el Tratado, en su apartado b) dice que por cannabis se entienden las sumiedades (las partes más altas) florales o con frutos de la planta de la cannabis, a excepción de las semillas y las hojas, en su apartado c) dice que por planta cannabis se entiende toda planta de genero cannabis, en su apartado d) que por resina de cannabis se entiende la resina separada del fruto o purificada. La lista I contiene entre los estupefacientes "la cannabis y sus resinas y los extractos o tintura de la cannabis", también incluido en la lista IV "cannabis y sus resinas." Por ello pudieron decir, con perfecta razón y adecuación a esta normativa, las sentencias de 27 de enero, 9 y 13 de junio y 6 de julio de 1983, que tanto la propia planta natural, mientras no se haya extraído sus sustancias y resinas, como éstas y sus preparados, constituyen el objeto del tráfico ilícito como estupefacientes, que el Convenio pretende combatir, añadiendo que entre las denominaciones vulgares de la cannabis, distintas en cada región o nación, es también conocida como hachís."

A la vista de todo lo anterior, resulta indiscutible la consideración del cannabis y todos sus derivados, en cualquiera de sus formas de preparación o presentación, como drogas de tráfico ilícito en el derecho penal español.

\section{CATEGORÍAS LEGALES EN FUNCIÓN DE LA NOCIVIDAD DE LA DROGA}

La ley penal española divide las drogas ilegales en dos categorías, atendiendo a la mayor o menor nocividad de las sustancias. La distinción fue introducida en la reforma del Código Penal del año 1983 y aplaudida por la mayoría de la doctrina penal. Se sanciona más gravemente el delito cuando tiene por objeto "sustancias que causan grave daño a la salud", siendo menores las penas cuando el tráfico se produce con otras drogas "blandas" no tan nocivas. Sin embargo, el Código no específica ni detalla cuales son las sustancias concretas consideradas legalmente como especialmente dañinas. Ha tenido que ser pues la jurisprudencia la que clasificara en una u otra categoría cada una de las drogas ilegales contenidas en los tratados internacionales ya mencionados.

La sustancia objeto de esta obra ha sido siempre calificada por el Tribunal Supremo como droga que no causa grave daño a la 
salud, con independencia de su forma de presentación o grado de concentración en THC. Hachis, marihuana, grifa y aceite de hachis han sido siempre catalogados jurisprudencialmente como drogas blandas, entre cientos más de resoluciones, en las STS de 4 de setiembre de 1983, 20 de febrero de 1984, 3 de diciembre de 1984, 24 de julio de 1991, 15 de octubre de 1991, 24 de setiembre de 1993 y 8 de noviembre de 1995 y 17 de octubre de 1996.

En la misma categoría de drogas escasamente dañosas se sitúan por la jurisprudencia la metacualona (STS de 28 de abril de 1994), el dextropropoxifeno (STS de 11 de febrero de 1991 y 29 de noviembre de 1993), el alprazolam (STS de 21 de diciembre de 1995, 5 de julio de 1997 y 1 de febrero de 1999) y, recientemente, el flunitrazepam (STS de 18 de mayo de 1998, 20 de julio de 1998).

Como drogas causantes de grave daño a la salud se consideran la heroína (STS de 17 de febrero de 1984, 23 de febrero de 1984, 12 de diciembre de 1984, 10 de julio de 1987, 18 de enero de 1991 y 23 de enero de 1992), la cocaína (STS de 25 de octubre de 1983, 8 de febrero de 1984, 29 de abril de 1985, 18 de noviembre de 1987 y 12 de julio de 1990), el LSD (STS de 5 de octubre de 1983, 8 de febrero de 1984, 11 de mayo de 1984, 1 de junio de 1984, 15 de febrero de 1988, 31 de marzo de 1990 y 28 de setiembre de 1992), las anfetaminas (STS de 20 de abril de 1996, 19 de octubre de 1996, 16 de abril de 1997, 1 de julio de 1997 y 3 de febrero de 1998) y las sustancias de diseño, MDMA (STS de 11 de octubre de 1993, 24 de enero de 1994, 31 de enero de 1994, 1 de junio de 1994, 25 de junio de 1994, 15 de noviembre de 1994, 12 de diciembre de 1994, 10 de enero de 1995, 15 de febrero de 1995, 3 de marzo de 1995, 6 de marzo de 1995, 17 de abril de 1995, 18 de mayo de 1995, 27 de setiembre de 1995, 14 de febrero de 1996 y 11 de setiembre de 1996), MDA (STS de 5 de febrero de 1996 y 25 de abril de 1996) y MDEA (STS de 27 de setiembre de 1994 y 1 de abril de 1996).

En relación con la distinción entre drogas más y menos nocivas, recientemente la juris- prudencia ha advertido que la inclusión de la sustancia en una u otra categoría legal debe ser alegada y justificada en cada proceso penal por la parte acusadora. Por ello, si la acusación se formula únicamente por delito de tráfico de drogas blandas, no puede el tribunal sentenciador condenar por tráfico de sustancias gravemente dañosas, dado que se vulneraría el denominado técnicamente principio acusatorio (STS de 28 de junio de 1999).

\section{TENENCIAY CONSUMO DE HACHIS}

El artículo 368 CP considera autores del delito de tráfico de drogas a quienes "ejecuten actos de cultivo, elaboración o tráfico, o de otro modo promuevan, favorezcan o faciliten el consumo ilegal de drogas tóxicas, estupefacientes o sustancias psicotrópicas o las posean con aquellos fines". Ello supone una extraordinaria amplitud de la conducta típica sancionable. Prácticamente cualquier actuación que propicie o permita el consumo de otra persona va a reputarse delictiva. Tan sólo quedan fuera del tipo penal el autoconsumo individual o colectivo de la sustancia y la tenencia previa necesaria para ese consumo propio.

El consumo de droga ni es actualmente ni ha sido nunca objeto de sanción penal en España, y lo mismo puede afirmarse de la tenencia previa al consumo. La redacción del artículo 344 CP dada por la Ley 44/1971 de 15 de noviembre, que estuvo vigente hasta la reforma operada por la Ley Orgánica 8/1983 de 25 de junio, incluía en la descripción de las acciones típicas delictivas la ejecución "ilegítimamente" de actos de tenencia de drogas, pero tal expresión siempre fue interpretada jurisprudencialmente en el sentido de restringirla a la tenencia preordenada a la distribución posterior de la sustancia ilícita (STS de 6 de abril de 1973, 5 de mayo de 1975 y 24 de noviembre de 1975, entre otras), advirtiendo nuestro Tribunal Supremo que "como el consumo de drogas o estupefacientes es atípico, para que la mera tenencia se repute delictiva, 
es menester que quede acreditado que la poseída no se hallaba destinada al propio consumo" (STS 20 de marzo de 1980). A partir de la reforma del Código de 1983, desapareció cualquier posible duda interpretativa, al eliminarse del texto del artículo la referencia a la "tenencia" de droga.

Conviene aquí precisar que la atipicidad penal de una conducta, tal como el autoconsumo y la tenencia de droga para ello, no obsta para que sea castigada en el ámbito administrativo, con multas y otras posibles sanciones no privativas de libertad. La Ley Orgánica 1/1992 de 21 de febrero, sobre Protección de la Seguridad Ciudadana, conocida popularmente como "Ley Corcuera", califica como infracciones administrativas, sin rango delictivo, las conductas que describe su artículo $25-1^{\circ}$, consistentes en "el consumo en lugares, vías, establecimientos o transportes públicos, así como la tenencia ilícita, aunque no estuviera destinada al tráfico, de drogas tóxicas, estupefacientes o sustancias psicotrópicas, siempre que no constituya infracción penal, así como el abandono en los sitios mencionados de útiles o instrumentos utilizados para su consumo". Esas conductas se califican como infracciones graves a la seguridad ciudadana y se sancionan administrativamente con multa de importe comprendido entre cincuenta mil una pesetas y cinco millones de pesetas, además de con otras sanciones no pecuniarias, según establece el artículo 28 de la Ley, cuyo análisis detallado se apartaría de la presente revisión de la legislación penal española sobre el cannabis y sus derivados.

Si la tenencia de droga resulta impune cuando está destinada únicamente al autoconsumo, y delictiva cuando, al contrario, se preordena a fines de distribución de la sustancia a otras personas, determinar cual de esas dos intenciones animaba en cada caso al poseedor de la droga va a resultar crucial en múltiples procesos penales, en los que se encuentra probada la tenencia de la sustancia pero sin acreditación directa de ningún acto de tráfico de la misma. Ha de realizarse entonces una valoración judicial del conjunto de pruebas disponibles para inferir el destino final de la droga poseída. Y en esa labor valorativa el Tribunal Supremo viene señalando como indicios fundamentales a examinar los siguientes:

a) condición o no de consumidor del portador de la droga y la acreditación de la cantidad habitualmente consumida por el mismo

b) cantidad de droga poseída

c) distribución de la droga en dosis listas para su posible venta y presentadas en la forma habitual en el mercado ilegal

d) tenencia de productos utilizados habitualmente para adulterar la droga

e) tenencia de instrumentos utilizados habitualmente para dividir la droga en dosis, tales como balanzas de precisión, cuchillos con señales de haber sido calentados para cortar mejor hachis, pajitas de plástico para contener cocaína, pequeños recortes de plástico para confeccionar bolsitas termoselladas con heroína, speed o cocaína, etcétera

f) circunstancias del hallazgo policial de la sustancia, lugar de aprehensión y razones del poseedor de la droga para encontrarse allí

g) incautación de cantidades notables de dinero sin procedencia lícita justificable

h) existencia en poder del poseedor de la droga o en su domicilio de notas o contabilidades manuscritas indicativas de ventas de drogas

i) grabaciones, con autorización judicial, de conversaciones telefónicas de esa persona relativas a operaciones de compraventa de drogas

j) trasiego continuo de consumidores de drogas en el domicilio de la persona a la que se le ocupa la sustancia, con visitas muy breves, como indicio de posibles operaciones de venta al menudeo

Del examen detenido de todo el material probatorio existente en cada caso ha de surgir, motivadamente, la convicción y decisión judicial sobre el destino o no al tráfico ilegal de la droga poseída. 
La alegación por la persona en posesión de la misma sobre su destino exclusivo al consumo propio habrá de ir acompañada de la demostración de su condición de consumidor de esa sustancia (STS de 2 de febrero de 1994 y 24 de mayo de 1996, entre muchas otras), mediante las oportunas pruebas documentales (historia clínica, enfermedades o padecimientos concomitantes o derivados de la drogodependencia, atención recibida en unidades o centros especializados de deshabituación, etc) y periciales (informe del médico forense u otros especialistas). A ser posible, convendrá también la acreditación, al menos de forma aproximada, de la cantidad habitualmente consumida por el sujeto.

Existencia del consumo y cantidad objeto del mismo serán, pues, dos extremos a probar para poder mostrar el destino de una sustancia al autoconsumo penalmente no sancionable, variando enormemente, en cada caso, la cantidad que cada persona pueda tener almacenada con esa finalidad. Sin embargo, el Tribunal Supremo ha establecido un límite cuantitativo, a partir del cual, como criterio general, se considera que la cantidad de la droga indica ya su destino al tráfico, por exceder de lo que un consumidor medio puede razonablemente tener en su poder en previsión de futuros consumos por su parte.

Se afirma por la jurisprudencia que "hay ánimo de traficar si se trata de una cantidad que excede de la que razonablemente está destinada al propio consumo, y que está objetivamente preordenada al tráfico, por exceder de las previsiones de consumo de un drogadicto" (STS de 2 de enero de 1998), y una corriente jurisprudencial viene manteniendo que ha de atenderse a la cantidad que pueda consumirse en cinco días como máxima admisible para el autoconsumo atípico, aplicando para cada día la dosis media ordinaria, según la droga concreta de que se trate en cada caso (STS de 5 de junio de 1997 y 16 de setiembre de 1997).

Con referencia al hachis la jurisprudencia considera como posiblemente dedicadas, en principio, al propio consumo tenencias de hasta 50 gramos de esta droga (STS de 17 de enero de 1986, 4 de diciembre de 1987, 9 de julio de 1988, 10 de noviembre de 1993, 19 de enero de 1995 y 20 de junio de 1997), si bien no faltan algunas resoluciones que absolvieron a personas acusadas tenedoras de cantidades superiores. En concreto, la STS de 8 de noviembre de 1991 consideró como destinados al autoconsumo 133 gramos de hachis, la STS de 26 de junio de 1993 absolvió al poseedor de 98 gramos de la droga y la STS de 12 de abril de 1996 lo hizo con un acusado en posesión de 241 gramos de la misma sustancia. Obviamente, se trataba de tres casos en los que no existía indicio ninguno complementario, de los antes expuestos, de posible destino al tráfico del hachis incautado.

Aunque con valor meramente anecdótico, merece cita la reciente sentencia de 27 de diciembre de 1999 dictada por el Juzgado de lo Penal 17 de Barcelona que decretó la absolución de un ciudadano austriaco, detenido por la policía en el aeropuerto de la ciudad, cuando embarcaba en un vuelo con destino a su patria, en posesión de 1.927 gramos de hachís, distribuido en ocho tabletas. Este acusado había sufrido cinco años antes la extirpación quirúrgica de un melanóma en la región umbilical, y al año siguiente una segunda operación para intervenirle un cáncer de estómago, siguiendo desde entonces un tratamiento con quimioterapia. La sentencia dictada consideró acreditado que el sujeto tomaba habitualmente 50 gramos semanales de hachís con el objeto "terapéutico" de aliviar el malestar sufrido a consecuencia de la quimioterapia, y entiende que no existe ningún indicio de que la droga, pese a la elevada cantidad poseída, estuviese dirigida al tráfico ilegal. Admite pues que se encontraba destinada únicamente al consumo propio de su poseedor y absuelve al mismo de la acusación formulada. La resolución está, en el momento de concluir estas líneas, en enero de 2000, recurrida en apelación por el ministerio fiscal ante la Audiencia Provincial de Barcelona, que habrá de dictar la sentencia definitiva sobre el caso. 


\section{CULTIVO DE CANNABIS}

El artículo 368 CP describe con extraordinaria amplitud el ámbito de conductas típicas en el delito de tráfico de drogas. La promoción, el favorecimiento o la facilitación, de cualquier modo, del consumo ilegal de drogas por otra persona, resulta, en principio, suficiente para subsumir esa conducta en el tipo penal. Quedan pues incluidos dentro del tipo penal, inicialmente, todos los actos que supongan cultivo, fabricación, venta, transmisión o donación de alguna sustancia considerada como droga, así como el transporte y la mera tenencia de esa droga si se realizan con finalidad ulterior de trafico.

El cultivo de la planta de cannabis es típico penalmente cuando se realiza con la intención de destinar posteriormente el producto obtenido a su difusión, venta o entrega a otras personas, de forma que el cultivo dirigido exclusivamente a proveer de droga para su consumo al propio cultivador resulta no punible (STS de 12 de diciembre de 1990 y 17 de enero de 1994).

Un caso peculiar tuvo lugar en Tarragona, donde una asociación partidaria de la legalización del cannabis, organizó en el año 1993 la plantación colectiva de cáñamo para su posterior recolección y consumo de la droga por los noventa y siete socios que participaban en la acción. Esta se ejecutó de forma pública por el grupo, legalmente constituido bajo la denominación Asociación Ramón Santos para el Estudio del Cannabis, y fue incluso objeto de información periodística. Seguido el procedimiento penal por el hecho, el mismo mereció sentencia absolutoria de la Audiencia Provincial de Tarragona. Recurrida por el ministerio fiscal en casación ante el Tribunal Supremo, este la revocó y condenó a los directivos de la asociación como organizadores de la plantación de la droga, con una fundamentación estrictamente técnico-jurídica, resaltando la naturaleza del tráfico de drogas como delito de peligro abstracto, que no exige ni la lesión efectiva ni, siquiera, el riesgo concreto del bien jurídico tutelado. Resulta pues irrelevante el posible error de subsun- ción típica del autor de la conducta, error que sería siempre irrelevante a los efectos del dolo. Concluye el Tribunal Supremo que "es claro que los acusados sabían lo que hacían y por lo tanto conocían los elementos del tipo, pues en su memoria explicativa de las actividades de la asociación expusieron su actividad de plantación de cáñamo índico en la finca de Riudecoms, como consta en los hechos probados. Quienes saben que cultivan cáñamo índico saben todo lo necesario para obrar con dolo en relación al art. $344 \mathrm{CP}$, a pesar de que puedan haber pensado que esta conducta no era la definida en el tipo penal como prohibida" (STS de 17 de noviembre de 1997).

\section{ACTOS DETRAFICO}

Tras el cultivo y recogida del producto del cannabis, son actos de tráfico de la droga cualesquiera que supongan entrega de la sustancia a otras personas. Examinaremos a continuación algunas cuestiones problemáticas.

Sobre el concepto de tráfico afirma la STS de 16 de junio de 1987 que "tráfico equivale a transmisión de una cosa a otra u otras personas, es decir, a traslación de la propiedad o posesión de las mismas, gratuita u onerosamente, total o parcialmente, directa o indirectamente, siempre y cuando, claro está, la transferencia implique promoción o favorecimiento del consumo de drogas tóxicas, estupefacientes o psicotrópicas".

El mero transporte de la droga, incluso sin interés económico por el transportista, constituye también acto típico penalmente, dado que contribuye a propiciar el consumo ilegal de la droga transportada por sus destinatarios finales. En tal sentido, afirma la STS de 30 de setiembre de 1997, que "asumir el encargo de transportar una cantidad de droga hasta una discoteca es poner una condición necesaria para cerrar el círculo de distribución de tal mercancía, y en su acto de tráfico del que se responde como autor". En el mismo senti- 
do, STS de 21 de enero de 1998 y 21 de febrero de 1998.

Los delitos de tráfico de drogas no requieren, en ningún supuesto, el ánimo de lucro en su autor. Por ello, la donación de droga ha sido considerada siempre como delictiva por la jurisprudencia (STS de 6 de abril de 1989, 19 de mayo de 1989, 22 de octubre de 1990, 4 de febrero de 1991, 3 de mayo de 1991, 25 de enero de 1992, 14 de octubre de 1993, 26 de noviembre de 1994 y 6 de junio de 1997). Sin embargo, hay casos especiales de entrega de drogas que el Tribunal Supremo ha considerado no sancionables penalmente. En general, se trata de la transmisión de dosis mínimas y gratuitamente a una persona que ya es previamente adicta a la sustancia, por parte de un familiar o persona allegada a dicho consumidor y con la intención de evitarle los sufrimientos del síndrome de abstinencia o de ayudarle a intentar una paulatina desintoxicaciòn mediante el consumo de dosis decrecientes (STS 2 de noviembre de 1992, 18 de diciembre de 1992, 29 de mayo de 1993, 15 de julio de 1993, 16 de setiembre de 1993, 6 de octubre de 1993, 16 de marzo de 1994, 8 de abril de 1994, 27 de mayo de 1994, 11 de junio de 1997, 14 de julio de 1997 y 22 de enero de 1998). Hay que advertir que en la casi totalidad de los casos examinados por la jurisprudencia, lo entregado habían sido cantidades muy pequeñas de heroína o cocaína, y no de hachís.

El consumo compartido de una droga entre usuarios habituales de la misma viene siendo también considerado no delictivo (STS de 12 julio de 1984, 6 de abril de 1989, 23 de marzo de 1991, 2 de noviembre de 1992, 25 de marzo de 1993, 27 de setiembre de 1993, 7 de febrero de 1994, 18 de setiembre de 1997 y 3 de noviembre de 1997). El Tribunal Supremo reputa igualmente atípicos los actos de compra colectiva de droga destinada al consumo de los que la adquieren (STS 25 de mayo de 1981, 11 de noviembre de 1992 y 27 de enero de 1995), e incluso, la compra por encargo de un grupo, del cual forma parte el encargado adquirente de la droga y destinando ésta al consumo de ese propio grupo (STS 18 de diciembre de 1992, 4 de febrero de 1993, 18 de octubre de 1993 y 3 de junio de 1994).

Conviene destacar que, dentro de la problemática probatoria al respecto, se plantea con frecuencia la valoración penal de la actuación de quien convive en el mismo domicilio con el autor directo de los actos de tráfico de drogas. La jurisprudencia es, en este punto, especialmente clara: la mera convivencia domiciliaria ni es, en si misma, un acto de cooperación con el traficante ni sirve de prueba de participación en los actos de tráfico.

La STS de 26 de julio de 1993 ya proclamaba que "el hecho de la unión matrimonial y el dato de viajar juntos no pueden ser, por sí solos determinantes de la inferencia de la participación de la esposa" en el tráfico ilícito llevado a cabo por el varón, sorprendido con la droga en el automóvil donde se hallaban ambos.

La STS de 30 de diciembre de 1993 afirma que "bajo la fuerza de los principios constitucionales, no puede admitirse ningún tipo de presunciones de participación. No es correcto ni ortodoxo en forma alguna atribuir al hombre el tráfico por el hecho de llevarlo a cabo la mujer o viceversa, por la circunstancia de la convivencia de ambos en el mismo piso o vivienda y el mayor o menor conocimiento que uno de ellos tenga del tráfico que realiza el otro. No se puede, por ello, atribuir la posesión de la droga para su venta o el tráfico de la misma indiscriminadamente a los dos. Hay que probar, fehacientemente y por medios plenos de aptitud incriminatoria o de cargo, que uno y otro llevaron a cabo actos que el legislador incorpora al núcleo de cada uno de los tipos en alguna de las modalidades de participación".

En el mismo sentido se ha pronunciado en bastantes más ocasiones la jurisprudencia. Incluso conociendo uno de los convivientes el tráfico desarrollado por otro en el domicilio, ello no le convierte en partícipe si no se demuestra una contribución concreta al hecho delictivo (STS de 13 de octubre de 1994, 14 de octubre de 1994, 20 de setiem- 
bre de 1995, 28 de noviembre de 1997 y 6 de octubre de 1998).

\section{PENAS APLICABLES}

El delito de tráfico de drogas que no causan grave daño a la salud, entre ellas todos los derivados cannábicos, se castiga en el artículo 368 CP con pena de prisión de duración comprendida entre uno y tres años $y$, además, con pena de multa, cuyo importe dependerá del valor de la droga objeto del delito: una vez calculado, se impondrá una multa de cuantía comprendida entre esa cifra y el doble de la misma. Ahora bien, el artículo 377 CP indica que a estos efectos ese valor de la droga "será el precio final del producto o, en su caso, la recompensa o ganancia obtenida por el reo, o que hubiera podido obtener".

En la práctica judicial son tenidos en cuenta, como medio probatorio fundamental, los informes que elabora semestralmente la Oficina Central Nacional de Estupefacientes, dependiente del Ministerio del Interior, relativos al precio medio de las drogas en el mercado ilícito. El último informe hasta la fecha de esta obra es el referido al segundo semestre de 1999 y en el mismo se indican, como precios medios en el mercado ilegal español los siguientes:

- Grifa comprada por gramos: 420 pesetas/gramo.
- Grifa comprada por kilos: 185.000 pesetas/kilogramo

- Hachís comprado por gramos: 640 pesetas/gramo

- Hachís comprado por kilos: 250.000 pesetas/kilogramo

- Aceite de hachís comprado por gramos: 2.000 pesetas/gramo

- Aceite de hachís comprado por kilos: 475.000 pesetas/kilogramo

A las penas de prisión y multa que se impongan en cada caso, ha de añadirse otra pena cuando el delito haya sido cometido por empresario, intermediario en el sector financiero, facultativo, funcionario público, trabajador social, docente o educador, en el ejercicio de sus respectivos cargos o profesiones. En estos casos, el artículo 372 CP, ordena imponer, además de las penas correspondientes ordinariamente al delito, la de "inhabilitación especial para empleo o cargo público, profesión u oficio, industria o comercio, de tres a diez años". A los efectos de este precepto, se consideran facultativos a los médicos, psicólogos, personas en posesión de título sanitario, veterinarios, farmacéuticos y sus dependientes.

Como supuesto todavía más grave, se impondrá, junto con la pena de prisión y la de multa, la pena de inhabilitación absoluta de diez a veinte años cuando el delito fuere realizado por una autoridad, o un agente de la autoridad, en el ejercicio de su cargo.

La condena por delito de tráfico de drogas conllevará, a tenor de lo dispuesto en el artí-

\begin{tabular}{|c|l|l|l|}
\hline \multicolumn{3}{|c|}{ CUADRO 2. PENAS APLICABLES EN EL DELITO DE TRAFICO DE CANNABIS } \\
\hline Penas & $\begin{array}{l}\text { TIPO BASICO } \\
\text { ART. 368 CP }\end{array}$ & $\begin{array}{l}\text { TIPOS AGRAVADOS } \\
\text { ART. 369 CP }\end{array}$ & $\begin{array}{l}\text { TIPOS ULTRAGRAVES } \\
\text { ART. 370 CP }\end{array}$ \\
\hline PRISION & $\begin{array}{l}\text { mínimo: } 1 \text { año } \\
\text { máximo: } 3 \text { años }\end{array}$ & $\begin{array}{l}\text { mín.: } 3 \text { años } \\
\text { máx.: } 4 \text { años y } 6 \text { meses }\end{array}$ & $\begin{array}{l}\text { mín.: } 4 \text { años y } 6 \text { meses } \\
\text { máx.: } 6 \text { años y } 9 \text { meses }\end{array}$ \\
\hline MULTA & $\begin{array}{l}\text { tanto al duplo } \\
\text { valor droga }\end{array}$ & $\begin{array}{l}\text { tanto al cuádruplo } \\
\text { valor droga }\end{array}$ & $\begin{array}{l}\text { tanto al séxtuplo } \\
\text { valor droga }\end{array}$ \\
\hline INHABILITACION ESPECIAL & $\begin{array}{l}\text { (para empleo o cargo público, profesión o comercio) } \\
\text { 3a 10 años }\end{array}$ \\
\hline INHABILITACION ABSOLUTA & $\begin{array}{l}\text { (si el hecho lo comete la autoridad en ejercicio de su cargo) } \\
10 \text { a 20 años }\end{array}$ \\
\hline
\end{tabular}


culo 374 CP, además de las penas señaladas, el comiso de las sustancias ilícitas, que serán posteriormente destruidas con arreglo al procedimiento reglamentariamente establecido. También serán objeto de decomiso los equipos y materiales utilizados para la elaboración de la droga y, en general, los vehículos, buques, aeronaves y otros posibles bienes y efectos de cualquier naturaleza que hayan servido de instrumento para la comisión del delito. Por último, serán igualmente decomi- sados todos los bienes provenientes del tráfico y las ganancias obtenidas con ellos, cualesquiera que sean las transformaciones que hayan podido experimentar.

Se exceptúan del comiso los bienes e instrumentos de lícita posesión que pertenezcan a un tercero de buena fe no responsable del delito, por ejemplo, el titular del vehículo que lo cede o alquila al autor del tráfico sin conocer que va a ser utilizado para la comisión del mismo.

\section{CUADRO 3. ARTíCULO 369 CÓdIGO PENAL ESPAÑOL}

Se impondrán las penas privativas de libertad superiores en grado a las respectivamente señaladas en el artículo anterior y multa del tanto al cuádruplo cuando:

$1^{\circ}$.Las drogas tóxicas, estupefacientes o sustancias psicotrópicas se faciliten a menores de dieciocho años o disminuidos psíquicos, o se introduzcan o difundan en centros docentes, en centros, establecimientos y unidades militares, en establecimientos penitenciarios o en centros asistenciales.

$2^{\circ}$. Los hechos fueren realizados en establecimientos abiertos al público por los responsables o empleados de los mismos.

$3^{\circ}$. Fueren de notoria importancia la cantidad de drogas tóxicas, estupefacientes o sustancias psicotrópicas objeto de las conductas a que se refiere el artículo anterior.

$4^{\circ}$.Las citadas sustancias o productos que faciliten a personas sometidas a tratamiento de deshabituación o rehabilitación.

$5^{\circ}$.Las referidas sustancias o productos se adulteren, manipulen o mezclen entre si o con otros, incrementando el posible daño a la salud.

$6^{\circ}$.El culpable perteneciere a una organización o asociación, incluso de carácter transitorio, que tuviere como finalidad difundir tales sustancias o productos aun de modo ocasional.

$7^{\circ}$.El culpable participare en otras actividades delictivas organizadas o cuya ejecución se vea facilitada por la comisión del delito.

$8^{\circ}$.El culpable fuere autoridad, facultativo, funcionario público, trabajador social, docente o educador y obrase con abuso de profesión, oficio o cargo.

$9^{\circ}$.Se utilice a menores de dieciséis años para cometer estos delitos.

Dispone también el Código Penal la posibilidad de que los bienes, efectos e instrumentos objeto del comiso puedan ser aprehendidos y puestos en depósito desde el primer momento del proceso penal por la autoridad judicial, con el fin de garantizar la efectividad del comiso. Incluso puede acordar el juez que durante la tramitación del procedimiento esos bienes puedan ser utilizados provisionalmente por la policía, con las debidas garantías para su conservación. Una vez sea definitivo el comiso, alcanzada la firmeza de la sentencia condenatoria en que se haya acordado, los bienes quedan adjudicados al Estado.

\section{TIPOS AGRAVADOS DE TRAFICO DE DROGAS}

Además de la distinción que efectúa el artículo 368 CP entre drogas "duras" y "blandas", el artículo 369 CP establece otra importante diferencia entre conductas básicas de tráfico de drogas y actuaciones especialmente graves. Al tipo básico de tráfico ilícito de cannabis le corresponden las penas ya examinadas. En los supuestos de tráfico especialmente grave las penas a imponer serán la de prisión con duración comprendida entre tres años y cuatro años y seis meses, y además la 
de multa de cuantía entre el valor de la droga y el cuádruplo del mismo.

Existen en el Código Penal nueve supuestos distintos de tráfico especialmente grave, recogidos en el citado artículo 369, de los cuales el que mayor problema interpretativo suscita es el de su apartado $3^{\circ}$, relativo a los casos en que "fuere de notoria importancia la cantidad de drogas tóxicas, estupefacientes o sustancias psicotrópicas objeto de las conductas a que se refiere el artículo anterior." Nos detendremos en su análisis.

El texto legal no se pronuncia sobre la cantidad de droga a partir de la cual se pueda considerar de notoria importancia, dejando pues su concreción a la labor jurisprudencial, que la ha situado en la cantidad que supondrían 200 dosis medias de cada tipo de droga. Con ese criterio, ha afirmado que la cantidad de notoria importancia sería la superior a 1.000 gramos de hachís (STS 8 de junio de 1984, 6 de noviembre de 1986, 23 de febrero de 1989, 28 de diciembre de 1990, 8 de octubre de 1991, 22 de setiembre de 1992, 28 de setiembre de 1995, 21 de octubre de 1996, 23 de julio de 1997).

El límite señalado jurisprudencialmente para el hachís varía para otros derivados cannábicos, ya que, como resume la STS de 12 de setiembre de 1997 "para la apreciación de la agravación específica de notoria importancia en las sustancias derivadas de la cannabis sativa ha de atenderse a la modalidad de la droga de que se trate, cifrándose aproximadamente en cinco kilogramos para la griffa o marihuana, un kilo para el hachís y 200 gramos para el aceite de hachís, ponderando las circunstancias de cada caso". En igual sentido se pronunciaron las STS de 17 de setiembre de 1993, 28 de abril de 1995, 8 de noviembre de 1995, 1 de marzo de 1996 y 17 de octubre de 1996.

La cuestión anterior se conecta con la posibilidad de tener en cuenta el grado de concentración o presencia de THC en la sustancia de que se trate para aplicar o no la agravación por la notoria importancia. Hay que recordar que en drogas como la heroína o la cocaína, lo que se tiene en cuenta para comprobar si se ha superado el tope jurisprudencial de la notoria importancia no es el peso total de la sustancia incautada sino la parte de ese peso correspondiente a droga pura, descontando la parte que corresponda a adulterantes o excipientes. De esa forma, de un alijo, por ejemplo, de 200 gramos de cocaína, con una pureza del $55 \%$, se computarán sólo los 110 gramos de sustancia pura, con lo que no se aplicará el tipo agravado, ya que este se inicia con los 120 gramos de esa droga, según reiterada jurisprudencia.

En el caso de los derivados cannábicos "el principio activo tetrahidrocannabinol (THC) es relevante en referencia a la notoria importancia de la droga, porque según sea el porcentaje de dicho principio, será mayor o menor el peso de la sustancia aprehendida a partir del cual pesará la agravación de notoria importancia, pero siempre referido al peso bruto de la sustancia, y por tanto no es el porcentaje de $\mathrm{THC}$ el que hay que tomar como base para determinar el peso neto y a partir de esa reducción aplicar a dicho peso el subtipo agravado" (STS de 3 de marzo de 1999).

La STS de 20 de noviembre de 1997 ponía de relieve que "a diferencia de lo que ocurre con la cocaína y la heroína, que son sustancias que se consiguen en estado de pureza por procedimientos químicos, los derivados del cáñamo índico o cannabis sativa, son productos vegetales que se obtienen de la propia planta sin proceso químico alguno, por lo que la sustancia activa tetrahidrocannabinol en estado puro nunca se contiene en su totalidad en las plantas o derivados. La concentración es diversa en cada una de las modalidades de presentación (marihuana, hachís y aceite) y por ello esta Sala ha optado por establecer el límite mínimo para la apreciación de la agravante específica, no en consideración a la sustancia activa, sino en relación con las diversas modalidades ya mencionadas. En cualquier caso no es el porcentaje de THC el que hay que tomar como base para determinar si el hachís alcanza o no el kilogramos que marca la línea divisoria, sino el peso bruto de la sustancia aprehendida, cualquiera que fuese su grado de concen- 
tración". En igual sentido se habían pronunciado las STS de 30 de octubre de 1995 y 6 de noviembre de 1995.

A modo de resumen, la STS de 12 de julio de 1999 concluye que "con relación a la marihuana, y a sus equivalentes la griffa o el kiffi marroquí, el principio activo THC se encuentra alrededor del 0,5 y el $2 \%$, y es en atención a esta escasa concentración que jurisprudencialmente se estima que el subtipo de notoria importancia operará a partir de cantidades superiores a 5 kilos por estimarse que, por lo general, el componente activo es cinco veces inferior al hachís; con relación al hachís, cuya concentración en principio activo suele estar entre el $4 \%$ y el $12 \%$, la aplicación del subtipo agravado será operativa de ordinario a partir de cantidades superiores al kilo y tratándose de aceite de hachís, cuya concentración de principio activo es superior al 12\%, la cantidad para la notoria importancia será inversamente proporcional".

La doctrina jurisprudencial sobre la frontera cuantitativa de la notoria importancia fue configurándose durante la vigencia del Código Penal de 1973, en cuyo antiguo artículo 344 bis a) $3^{\circ}$ se establecía el tipo agravado a que nos venimos refiriendo. Al producirse la entrada en vigor del nuevo Código de 1995, que elevó, en general, las penas imponibles en los delitos de tráfico de drogas, se planteó la posibilidad de elevar, correlativamente, los límites jurisprudenciales de la notoria importancia. Sin embargo, el Tribunal Supremo ha optado, desde el mes de febrero de 1999, por mantener el criterio ya asentado sobre los topes de cada sustancia a partir de los cuales ha de aplicarse el tipo delictivo agravado (STS de 18 de febrero de 1999, 17 de marzo de 1999 y 12 de mayo de 1999).

\section{TIPOS ULTRA AGRAVADOS DE TRAFICO}

Existe un tipo ultraagravado de tráfico, contemplado en el artículo $370 \mathrm{CP}$, castigado con pena de prisión de duración mínima de cuatro años y seis meses, y máxima de seis años y nueve meses, además de multa con cuantía comprendida entre el valor de la droga y su séxtuplo. Este tipo especialmente grave se aplica en dos supuestos: cuando las conductas de tráfico de drogas, además de encajar en algún tipo agravado del artículo 369 CP, revistan extrema gravedad, y cuando los reos hayan actuado como jefes de organizaciones delictivas dedicadas al tráfico.

Hay que advertir que el texto legal no ofrece ningún detalle sobre el concepto jurídico indeterminado "conductas de tráfico de extrema gravedad", en otra laguna más que ha debido cubrir la jurisprudencia. En algunas ocasiones, el Tribunal Supremo ha señalado que para considerar la conducta de extrema gravedad ha de existir una cantidad elevadísima de droga, que sea al menos 100 veces el límite de la notoria importancia. Aunque en tales ocasiones la droga en cuestión era cocaína o heroína, la generalización del mismo criterio permite establecer que, en el caso del hachís, se requeriría, en todo caso, al menos 100 kilos de la droga. Sin embargo, ese único dato cuantitativo no permite apreciar el tipo ultra-agravado si no va unido a otros datos, tales como la existencia de una organización criminal bien estructurada y la utilización de medios o métodos especialmente sofisticados o aptos para ejecutar impunemente el delito, entre ellos, como ejemplo más característico, "el uso de grandes elementos de transporte especialmente preparados para el tráfico ilícito, como fletaje de barcos, camiones de un cierto tonelaje, etc" (STS de 20 de marzo de 1999).

Afirma la STS de 30 de mayo de 1997 que "a partir de la cantidad de notoria importancia se ha de agregar alguna otra circunstancia objetiva y subjetiva que, según la experiencia, permita deducir un especial merecimiento de pena superior a la imponible por la simple aplicación de la notoria importancia". En este caso se trataba del transporte por barco de cuatro toneladas de hachís y se aplicó el tipo ultra agravado.

La STS de 6 de junio de 1997 aplicó este tipo ultra grave en un caso de transporte de 900 kilos de hachís, señalando que "la extre- 


\section{CUADRO 4. ARTículo 370 Código PENAL}

Los Jueces o Tribunales impondrán las penas privativas de libertad superiores en grado a las señaladas en el artículo anterior y multa del tanto al séxtuplo cuando las cuando las conductas en él definidas sean de extrema gravedad, o cuando se trate de los jefes, administradores o encargados de las organizaciones o asociaciones mencionadas en su número $6 .^{\circ}$. En este último caso, así como cuando concurra el supuesto previsto en el número $2{ }^{\circ}$ del mencionado artículo, la autoridad judicial podrá decretar, además, alguna de las medidas siguientes:

Disolución de la organización o asociación o clausura definitiva de sus locales o de los establecimientos abiertos al público.

Suspensión de las actividades de la organización o asociación, o clausura de los establecimientos abiertos al público por tiempo no superior a cinco años.

Prohibición a las mismas de realizar aquellas actividades, operaciones mercantiles o negocios, en cuyo ejercicio se haya facilitado o encubierto el delito, por tiempo no superior a cinco años.

ma gravedad por la notoria importancia debería apoyarse en otros fundamentos distintos del puramente cuantitativo, aunque indirectamente siempre estén relacionados con el concepto cantidad. Tales pueden ser a) la concurrencia de alguno de los supuestos del artículo 344 bis-a antiguo o art. 369 nuevo; b) la utilización de especiales métodos previamente preparados para el ilícito tráfico, como en el caso de ahora pudiera ser la sofisticada manera con la que los fardos fueron arrojados al mar desde la patera, con un motor fuera borda de $40 \mathrm{~cm}$. cúbicos, que los acusados llevaban; c) la posibilidad de que la cantidad intervenida afecte a un número muy alto de consumidores, como ahora acontece, aun cuando no se oculte que tal dato irá siempre indefectiblemente unido a la cantidad, lo que igualmente acontece ante la posibilidad de que el género estuviere destinado a constituir una fuente de suministro de larga duración".

Últimamente, la STS de 10 de mayo de 1999 excluyó la aplicación de este subtipo ultra agravado en un caso en que lo poseído eran 1.550 kilos de hachís. Señala, con carácter general, esta resolución, refiriéndose a la extrema gravedad, que "tal concepto jurídico indeterminado exige una aplicación restrictiva y una minuciosa observación de las circunstancias del caso. Desde luego no es bastante sólo el criterio de la cantidad de droga objeto del ilícito tráfico, porque se corre el riesgo de apreciar repetidamente la agravación ya citada de notoria importancia, aunque, claro es, que una cantidad que rebasara en mucho la simple notoriedad de la cantidad de droga pueda ser una base correcta para apreciar la extrema gravedad, siempre que, además, el volumen de la sustancia objeto de ilícito tráfico sobre el mercado pudiera alterar o altere, desbordándolo, lo que pudiera considerarse un abastecimiento normal agravando hasta extremos extraordinarios la gravedad para la salud pública, y cuando se acompañara, además, de elementos de transporte relevantes y especialmente dispuestos para este tráfico que facilitaran una mayor eficacia del tráfico que se realice." Después de sentar esos criterios generales, en términos a nuestro juicio no muy precisos, descarta la aplicación de la agravación en el supuesto concreto, porque la cantidad de hachís aprehendida, aunque elevada, no lo fue tanto como en los casos de otras sentencias "sin que pueda afirmarse con certeza que pudiera haber determinado de forma excepcional al mercado ilícito de una droga de consumo bastante extendido socialmente como es el hachís y, de otro lado, aunque se utilizaron para transportarla pateras dotadas de potentes motores fueraborda de 60 y 75 caballos de fuerza, al final de la operación toda la droga se llevaba por un solo tripulante en una sola de ellas aunque fuera la de motor más potente". 


\section{CONCLUSIONES}

El examen efectuado de la regulación en el derecho penal español y de la producción jurisprudencial sobre el cannabis y sus derivados nos permite alcanzar las siguientes conclusiones:

a) El derecho español considera como drogas ilícitas las sustancias definidas como tales en los Convenios internacionales sobre la materia, entre las que se incluyen el cannabis y todos sus derivados y preparaciones con efectos psicoactivos.

b) El consumo de las drogas mencionadas es ilegal en España, por lo que puede ser sancionado administrativamente con multas, sin embargo, no constituye delito. Tampoco es delito la tenencia de dichas sustancias destinada al autoconsumo de su poseedor y sin ánimo de transmisión a otras personas, pero esa intención de tráfico de la sustancia se presume cuando se trata de más de 50 gramos de hachís.

c) Se entiende por tráfico de drogas cualquier acción de difusión, distribución o entrega de la sustancia a otras personas, o de favorecimiento del consumo ilegal por ellas. El tráfico de drogas se califica como delito y se castiga con penas de prisión y multas, cuya severidad depende, en parte, de la nocividad de la sustancia y, en parte, de la gravedad de la conducta delictiva. El Código Penal distingue entre drogas "duras" gravemente dañosas para la salud y drogas "blandas" que no causan ese grave daño. Por otro lado, diferencia las conductas básicas de tráfico de drogas de otras actuaciones más graves.

d) El cannabis y sus derivados se incluyen en la categoría legal de sustancia no causante de grave daño a la salud, y su tráfico se sanciona con penas de prisión de duración comprendida, en principio, entre uno y tres años, además de multa y otras posibles penas accesorias de menor entidad.

e) Los delitos de tráfico de cannabis se sancionan más gravemente cuando la cantidad de sustancia objeto del tráfico excede de un kilogramo de hachís, en cuyo caso la pena a imponer va desde tres años hasta cuatro años y medio de prisión. En casos excepcionales de tráfico a gran escala por parte de bandas organizadas, la pena máxima que puede aplicarse llega a los seis años y nueve meses de prisión. 